\title{
An operon encoding a novel ABC-type transport system in Bacillus subtilis
}

\author{
Francesco Rodriguez and Guido Grandi
}

Author for correspondence: Guido Grandi. Tel: +39 2 5205970. Fax: +39 252022974.

ENIRICERCHE S.p.A. Genetic Engineering and Microbiology Laboratories, Via F. Maritano, 26 San Donato Milanese 20097, Milan, Italy

\begin{abstract}
Downstream from the surfactin synthetase operon in Bacillus subtilis a new operon-type structure has been localized which, on the basis of sequence determination, potentially encodes an ABC-type transport system. The 268 amino acid protein, the product of orf1, represents the solute-binding component of the system whereas the orf 2 product, a 234 amino acid protein, is the transmembrane component. Finally orf 3 potentially encodes a typical 241 amino acid ATP-binding protein involved in energy supply. Comparison of the three proteins with the subunits of other ABC-type systems suggests that this new system is involved in amino acid transport.
\end{abstract}

Keywords : transport systems, amino acid binding, ATP binding, lipoproteins, Bacillus subtilis
In Gram-negative bacteria numerous solutes such as sugars, amino acids, peptides, anions and metals are transported across the cytoplasmic membrane by the ABC-type (or ATP-binding cassette type) multicomponent transport systems. The common protein components of these systems include two transmembrane proteins that usually span the membrane about six times each, one or two peripheral-membrane ATP-binding protein(s) localized on the cytoplasmic side of the membrane and a high-affinity solute-binding protein which, in Gram-negative bacteria, is periplasmic. The function of the transmembrane component is to channel the solute to the cytoplasm whereas the ATP-binding protein provides energy to the system. Finally, the ligandbinding protein confers specificity and affinity (Higgins, 1992).

The presence of ABC-type transport systems in Grampositive bacteria has only recently been documented. In particular, among the most extensively characterized are the ami $A$ system of Streptococcus pneumoniae (Alloing et al., 1990) responsible for the uptake of oligopeptides, the oligopeptide transport systems $s p o O K$ and $a p p$ of Bacillus subtilis (Perego et al., 1991; Rudner et al., 1991; Koide \& Hoch, 1994), the $r b s$ and $\operatorname{dci} A$ systems of $B$. subtilis (Woodson \& Devine, 1994; Mathiopoulos et al., 1991), the function of which is to transport ribose and dipeptides, respectively, and the glutamine transport system of Bacillus stearothermophilus (Wu \& Welker, 1991). On the basis of the information obtained from the characteriz-

The EMBL accession number for the nucleotide sequence reported in this paper is $\mathrm{X} 77636$. ation of these systems it appears that their overall structural organization highly resembles their Gramnegative counterparts. The most relevant difference is found in the solute-binding proteins. In fact in Grampositive bacteria they are lipoproteins anchored to the external surface of the cell membrane with an $\mathrm{N}$-terminal glyceride-cysteine (for a review see von Heijne, 1989).

In the course of our sequencing work on the surfactin synthetase operon (Cosmina et al., 1993; van Sinderen et al., 1993) we identified an operon-type structure potentially encoding three proteins which, on the basis of sequence homology, are likely to form an ABC-type amino acid transport system. This putative operon is located upstream from the sfp gene. A partial characterization of this region has been recently reported by Grossman et al. (1993), who found it to be part of a B. subtilis chromosomal region able to complement siderophore-deficient mutants of Escherichia coli. Interestingly the authors demonstrated that the complementing factor was the product of the sfp gene.

To our knowledge, this is the first putative amino acid transport system fully characterized in B. subtilis.

A 300 bp Sau3A fragment located approximately $3.3 \mathrm{kbp}$ downstream from the $\operatorname{srf} A$ operon was inserted into the Bam HI site of the integrative plasmid pJM103 (Perego et al., 1991). The recombinant plasmid was then used to transform $B$. subtilis strain 168, selecting for chloramphenicol-resistant clones. From one of the transformants which, upon Southern blot and PCR analyses, turned out to have the plasmid correctly inserted (data not shown), the chromosomal DNA was prepared, digested with PstI and self-ligated. The ligase mixture was utilized 


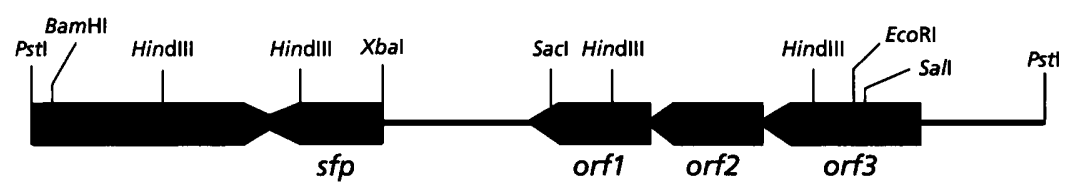

$1 \mathrm{~kb}$
Fig. 1. Physical map and genetic organization of the $6 \mathrm{~kb}$ region located downstream from the srfA operon (Cosmina et al., 1993). orf1, orf2 and orf3 code for the three protein subunits constituting the $A B C$ type transport system. to transform $E$. coli JM109 competent cells and among the several tranformants obtained six were analysed for plasmid content. Plasmid analysis showed that five of the randomly selected clones harboured a plasmid containing the same chromosomal fragment of approximately $6 \mathrm{~kb}$. One of these plasmids, named pSM714, was further characterized.

The sequencing of the $5828 \mathrm{bp}$ fragment was accomplished using the dideoxy chain-termination procedure (Sanger et al., 1977) and the Sequenase version 2.0 enzyme (USB) on pSM714 derivatives obtained upon progressive ExoIII deletions of the cloned region (Henikoff, 1984). The fragment was sequenced on both strands with a mean of three readings per base.

Fig. 1 shows the physical and genetic map of the region within which, approximately $850 \mathrm{bp}$ upstream from $s f p$, three ORFs (orf1, orf 2 and orf 3 ), probably organized in a single transcriptional unit, were found. The nucleotide sequence of orf1, orf 2 and $\operatorname{orf} 3$ is given in Fig. 2. The 804 bp long orf 1 potentially codes for a protein of 268 amino acids whereas orf 2 is $702 \mathrm{bp}$ in length (protein of 234 amino acids). The $3^{\prime}$ end of orf 1 and the $5^{\prime}$ end of orf 2 overlap by $11 \mathrm{bp}$. orf 3 is $741 \mathrm{bp}$ long and is located $13 \mathrm{bp}$ downstream from the $3^{\prime}$ end of orf2. Putative ribosomebinding sites were found upstream from the ATG start codon of both orf 1 and orf 3 (underlined in Fig. 2) whereas the orf 2 start codon appears to be preceded by a less canonical sequence. Two putative rho-independent terminator structures are located downstream from orf 3 with a calculated $\Delta G$ value of $-24.2 \mathrm{kcalmol}^{-1}$ $\left(-101.64 \mathrm{~kJ} \mathrm{~mol}^{-1}\right)$ and $-18.2 \mathrm{kcalmol}^{-1}(-76.44$ $\left.\mathrm{kJ} \mathrm{mol}{ }^{-1}\right)$, respectively. Finally, a putative $\sigma^{\mathrm{A}}$ promoter (TTGTAA-18 bp-TAAAAT) located $23 \mathrm{bp}$ upstream from the orf1 start codon might function as the transcriptional start for the three genes. Although not further discussed here, two additional ORFs, one located upstream from orf1 and the other downstream from orf3, are present in the $6 \mathrm{kbp}$ Pst I fragment.

When the homologies of Orf1, Orf2 and Orf3 with other proteins were analysed it appeared that the three proteins are likely to form an ABC-type transport system. In particular, Orf1 represents the solute-binding component of the system, sharing homology with the glutaminebinding subunit GlnH of E. coli (31\% identity) (Nohno et al., 1986), the arginine- and histidine-binding subunits ArgT and His J of Salmonella typhimurium (26\% and $25 \%$ identity, respectively) (Higgins et al., 1982) and the glutamine-binding subunit of $B$. stearotbermophilus $(21 \%$ identity) (Wu \& Welker, 1991). Relevant homologies were also found with other solute-binding components such as Noc'T and Occ'T of Agrobacterium tumefaciens (23\% and $21 \%$ identity, respectively) (Valdivia et al., 1991; Zanker $e$ al., 1992) and Art J and ArtI of E. coli (24\% and $27 \%$ identity, respectively) (Wissenbach et al., 1993). Interestingly, Orf1 has a typical leader sequence for secretion and the potential cleavage site (LAA-CGA) corresponds to the consensus sequence for the precursors of lipoproteins (von Heijne, 1989).

Orf2 has significant homology with the $g \ln P$ gene product of $E$. coli (38\% identity) and with the bis $Q$ and $b i s M$ gene products of $S$. typhimurium $(27 \%$ and $32 \%$ identity, respectively). Like these proteins, Orf2 has six putative transmembrane domains, suggesting that it might function as the transmembrane homodimer component of the transport system.

Finally, Orf3 is the typical ATP-binding component of the ABC-type transport systems. It shares $55 \%$ identity with $G \ln Q$ of $E$. coli, $54 \%$ identity with $G \ln Q$ of $B$. stearothermophilus and $51 \%$ identity with HisP of $S$. typhimurium.

In conclusion, the three gene products here described appear to constitute a new $B$. subtilis ABC-type transport system. Orf1 is the solute-binding component tethered to the cell membrane with an N-terminal glyceride-cysteine, Orf2 forms the transmembrane complex (probably homodimeric) and Orf3 provides the system with energy.

Tam \& Saier (1993) have recently reviewed the structural, functional and evolutionary characteristics of the extracellular solute-binding receptors in bacteria, which were grouped in eight distinct families. According to this classification Orf1 appears to belong to receptor family 3, which recognizes and transports polar amino acids and opines, on the basis of its size, typical for this family $(265 \pm 12$ residues), and of the degree of homology. In particular, one of the two signature sequences which characterize family 3 [GF(DE)(LIV)DLX3(LIVM) $(\mathrm{CA})(\mathrm{KE})]$ is partially conserved in Orf1 between residues 70 and 81 .

The homology of Orf1 with the receptor subunits of the polar amino acid and opine transport systems so far characterized together with the striking similarities of Orf2 and Orf3 with the other components of the same systems lead us to hypothesize that this system is involved in amino acid transport.

Unfortunately, we do not have any direct experimental evidence to unequivocally assign a specific function to this 


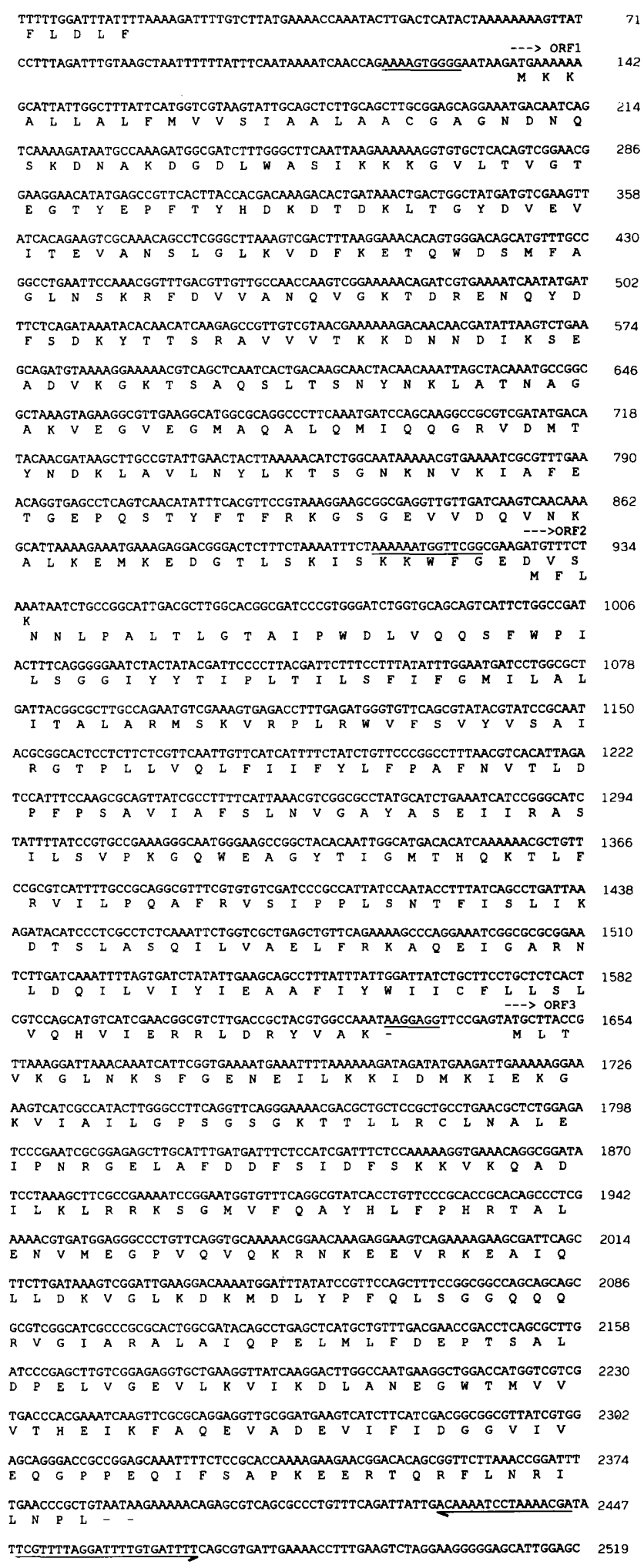

ACAGCGAATGTTAAATTCGTGAGCACTGAAGCACAGGCCTGACAACGAATGCAAGGGTTTGCCAACACGCTG 2591

AAACAGGGCGCCTGCGGCCCTGTTTTTTTGTT

2623

Fig. 2. Nucleotide sequence and deduced amino acid sequence of the region upstream from the sfp gene potentially encoding an ABC-type transport system. Putative ribosome-binding sites (underlined), the start codons of orf1, orf2 and orf 3 and the two rho-independent terminators (underlined with arrows) are indicated. system. When the chromosomal deletion of a $1148 \mathrm{bp}$ HindIII fragment, which destroys both the $\mathrm{C}$-terminus of Orf1 and the N-terminus of Orf3 and removes Orf2 entirely, was introduced into B. subtilis 168 and the mutant strain was grown in minimal media containing different amino acids as the sole nitrogen source no difference in the growth curves of the mutant strain with respect to the wild-type strain was observed. However these results do not rule out the involvement of the system in amino acid transport since, as it is the case for other organisms (see for example Townsend \& Wilkinson, 1992), each amino acid might have more than one transport system. More detailed physiological and biochemical studies are necessary to identify the function of the system.

\section{ACKNOWLEDGEMENTS}

We would like to thank $\operatorname{Dr} A$. Sonenshein for helpful discussions. The expert secretarial assistance of E. Iennaco is also acknowledged. This work was financially supported partially by the EEC Bacillus Genome Sequencing Project and partially by ENIRICERCHE S.p.A.

\section{REFERENCES}

Alloing, G., Trombe, M.-C. \& Claverys, J.-P. (1990). The ami locus of the Gram-positive bacterium Streptococcus pneumoniae is similar to binding protein-dependent transport operons of Gram-negative bacteria. Mol Microbiol 4, 633-644.

Cosmina, P., Rodriguez, F., de Ferra, F., Grandi, G., Perego, M., Venema, G. \& van Sinderen, D. (1993). Sequence and analysis of the genetic locus responsible for surfactin synthesis in Bacillus subtilis. Mol Microbiol 8, 821-831.

Grossman, T. H., Tuckman, M., Ellestad, S. \& Osburne, M. S. (1993). Isolation and characterization of Bacillus subtilis genes involved in siderophore biosynthesis: relationship between $B$. subtilis sfp $p^{0}$ and Escherichia coli entD genes. J Bacteriol 175, 6203-6211. von Heijne, G. (1989). The structure of signal peptides from bacterial lipoproteins. Protein Eng 2, 531-534.

Henikoff, S. (1984). Unidirectional digestion with exonuclease III creates targeted breakpoints for DNA sequencing. Gene 28, 351-359.

Higgins, C. F. (1992). $A B C$ transporters: from microorganisms to man. Annu Rev Cell Biol 8, 67-113.

Higgins, C. F., Haag, P. D., Nikaido, K., Ardeshir, F., Garcia, G. \& Ferro-Luzzi Ames, G. (1982). Complete nucleotide sequence and identification of membrane components of the histidine transport operon of S. typhimurium. Nature 298, 723-727.

Koide, A. \& Hoch, J. A. (1994). Identification of a second oligopeptide transport system in Bacillus subtilis and determination of its role in sporulation. Mol Microbiol 13, 417-426.

Mathiopoulos, C., Mueller, J. P., Slack, F. J., Murphy, C. G., Patankar, S., Bukusoglu, G. \& Sonenshein, A. L. (1991). A Bacillus subtilis dipeptide transport system expressed early during sporulation. Mol Microbiol 5, 1903-1913.

Nohno, T., Saito, T. \& Hong, J.-S. (1986). Cloning and complete nucleotide sequence of the Eschericbia coli glutamine permease operon (glnHPQ). Mol \& Gen Genet 205, 260-269.

Perego, M., Higgins, C. F., Pearce, S. R., Gallagher, M. P. \& Hoch, J. A. (1991). The oligopeptide transport system of Bacillus subtilis plays a role in the initiation of sporulation. Mol Microbiol 5, $173-185$. 
Rudner, D. Z., LeDeaux, J. R., Ireton, K. \& Grossman, A. D. (1991).

The spoOK locus of Bacillus subtilis is homologous to the oligopeptide permease locus and is required for sporulation and competence. J Bacteriol 173, 1388-1398.

Sanger, F., Nicklen, S. \& Coulson, A. R. (1977). DNA sequencing with chain-terminating inhibitors. Proc Natl Acad Sci USA 74, 5463-5467.

van Sinderen, D., Galli, G., Cosmina, P., de Ferra, F., Withoff, S., Venema, G. \& Grandi, G. (1993). Characterization of the $\operatorname{srf} A$ locus of Bacillus subtilis: only the valine-activating domain of $\operatorname{srf} A$ is involved in the establishment of genetic competence. Mol Microbiol 8, 833-841.

Tam, R. \& Saier, M. H., Jr (1993). Structural, functional, and evolutionary relationships among extracellular solute-binding receptors of bacteria. Microbiol Rev 57, 320-346.

Townsend, D. E. \& Wilkinson, B. J. (1992). Proline transport in Stapbylococcus aureus: a high-affinity system and a low-affinity system involved in osmoregulation. $J$ Bacteriol 174, 2702-2710.
Valdivia, R. H., Wang, L. \& Winans, S. C. (1991). Characterization of a putative periplasmic transport system for octopine accumulation encoded by Agrobacterium tumefaciens Ti plasmid pTiA6. $J$ Bacteriol 173, 6398-6405.

Wissenbach, U., Keck, B. \& Unden, G. (1993). Physical map location of the new artPIQMJ genes of Escherichia coli, encoding a periplasmic arginine transport system. $J$ Bacteriol 175, 3687-3688.

Woodson, K. \& Devine, K. M. (1994). Analysis of a ribose transport operon from Bacillus subtilis. Microbiology 140, 1829-1838.

Wu, L. \& Welker, N. E. (1991). Cloning and characterization of a glutamine transport operon of Bacillus stearothermophilus NUB36: effect of temperature on regulation of transcription. J Bacteriol 173, $4877-4888$.

Zanker, H., von Lintig, J. \& Schröder, J. (1992). Opine transport genes in the octopine (occ) and nopaline (noc) catabolic regions in Ti plasmids of Agrobacterium tumefaciens. J Bacteriol 174, 841-849.

Received 5 January 1995; revised 6 March 1995; accepted 22 March 1995. 